\title{
Comparative study of saturating power boriding media of different composition
}

\author{
I.A. Garmaeva ${ }^{1}$, A.M. Guriev ${ }^{1,2, \dagger}$, T.G. Ivanova ${ }^{1}$, M.A. Guriev ${ }^{1}$, S.G. Ivanov ${ }^{1}$ \\ †gurievam@mail.ru
}

\begin{abstract}
${ }^{1}$ Altai State Technical University after I.I. Polzunov, prospect Lenin 46, 656038 Barnaul, Russia
${ }^{2}$ Wuhan Textile University, 1 FangZhi Road, China 430073 Wuhan, China
\end{abstract}

\begin{abstract}
Boriding abilities of boriding media based on boron carbide, amorphous boron and mixtures for a simultaneous saturation by boron, chromium and titanium have been compared. As an object of study boride coatings on carbon steels 45 and U8A have been chosen. Borating was done from powder mixtures in a chamber furnace of SNOL type. The microstructure and thickness of the diffusion coatings were studied on cross microsections by means of optical microscopy. The boride phases were identified by «color etching» and by X-ray diffraction. It is shown that during simultaneous saturation of carbon steels with boron, chromium and titanium the diffusion processes occur much more intensively. Addition of carbide-forming elements such as chromium and titanium into a boriding mixture results in a significant acceleration of boron diffusion in carbon steels 45 and U8A. During a simultaneous multicomponent saturation with boron, titanium and chromium the rate of diffusion layer formation on carbon steels is higher than under one-component boriding. In the case of a multicomponent saturation by boron along with strong carbide-forming elements (chromium and titanium), an increase of the carbon content of carbon steel under saturation from 0.45 to $0.8 \mathrm{wt}$.\% has little effect on the formation of a diffusion layer. While in the case of one-component boriding the carbon content of the steel significantly affects both the thickness and microstructure of a boride coating, during a simultaneous saturation with boron, titanium and chromium the carbon content of the steel has practically no effect on the diffusion coating thickness.
\end{abstract}

Keywords: steel, diffusion, hardening, boron.

\section{Сравнительное исследование насыщающей способности борирующих сред различного состава}

\author{
Гармаева И.А. ${ }^{1}$, Гурьев А.М. ${ }^{1,2, \dagger}$, Иванова Т.Г. ${ }^{1}$, Гурьев M.А. ${ }^{1}$, Иванов С.Г. ${ }^{1}$ \\ ${ }^{1}$ ФБГОУ ВО Алтайский государственный технический университет им. И.И. Ползунова, \\ пр-т Ленина 46, 656038 Барнаул, Россия \\ ${ }^{2}$ Уханьский текстильный университет, улица ФангЖи, 1, 430073 Ухань, Китай
}

\begin{abstract}
Проведено сравнение борирующей способности насыщающих сред для борирования на основе карбида бора и аморфного бора, а также смеси для одновременного насыщения бором, хромом и титаном. В качестве объекта изучения были выбраны боридные покрытия на углеродистых сталях 45 и У8А. Борирование производили из порошковых смесей в камерной печи типа СНОЛ. Исследование микроструктуры и толщины диффузионных покрытий производили на поперечных микрошлифах при помощи оптической микроскопии. Идентификацию боридных фаз производили методом “цветного травления” и при помощи рентгеновской дифрактометрии. Показано, что при одновременном насыщении бором, хромом и титаном углеродистых сталей, диффузионные процессы протекают значительно интенсивнее. Введение в состав борирующей смеси карбидообразующих элементов - хрома и титана способствует значительному ускорению процессов диффузии бора в углеродистых сталях 45 и У8А. При одновременном многокомпонентном насыщении бором, хромом и титаном скорость образования диффузионного слоя на углеродистых сталях выше, чем при борировании. В случае многокомпонентного насыщения бором совместно с сильными карбидообразующими элементами (хром и титан) увеличение содержания углерода в насыщаемой углеродистой стали от 0,45 до 0,8 мас.\% оказывает слабое влияние на процесс образования диффузионного слоя. Если при однокомпонентном борировании содержание углерода в стали значительно влияет как на толщину, так и на микроструктуру боридного покрытия, то при одновременном насыщении бором, хромом и титаном содержание углерода в стали практически не оказывает влияния на толщину диффузионного покрытия.
\end{abstract}

Ключевые слова: сталь, диффузия, упрочнение, бор. 


\section{1. Введение}

Повышение ресурса работы рабочих органов и деталей машин является как актуальной научной проблемой современного материаловедения, так и задачей машиностроительной отрасли. Среди множества способов поверхностного упрочнения большое внимание привлекают способы химико-термической обработки (XTO). Перспективными способами ХTO являются борирование, а также совмещенные процессы - борохромирование, боротитанирование, бороалитирование и т.д. В литературе, как отечественной, так и в зарубежной, дается множество рекомендаций как по технологическим параметрам, так и по составам для диффузионного борирования и процессов насыщения бором совместно с хромом, титаном и другими элементами. При этом сравнительных данных как по скорости формирования диффузионных покрытий, так по их структуре и фазовому составу мало. В данной работе сделана попытка сравнить насыщающую способность смесей для борирования на основе карбида бора и аморфного бора а также смеси для одновременного насыщения бором, хромом и титаном.

\section{2. Методика эксперимента}

В работе проведено сравнение насыщающей способности сред для диффузионного борирования и одновременного насыщения бором, хромом и титаном следующего состава:

$80 \% \mathrm{~B}_{4} \mathrm{C}+2 \% \mathrm{NaF}+18 \% \mathrm{Al}_{2} \mathrm{O}_{3}$

$63 \% \mathrm{~B}+2 \% \mathrm{NaF}+35 \% \mathrm{Al}_{2} \mathrm{O}_{3}$

(№ 1)

$80 \% \mathrm{~B}_{4} \mathrm{C}+2 \% \mathrm{NaF}+10 \% \mathrm{Cr}+8 \% \mathrm{Ti} \quad$ (№ 3)

По результатам анализа как зарубежных так и отечественных публикаций, содержание бора во всех смесях было приведено к 63\% масс., содержание активатора, в качестве которого был взят фторид натрия, выбрали на минимальном уровне $2 \%$ масс., хром и титан были взяты на уровне 10 и 8 масс.\%. Оксид алюминия являлся балластной добавкой, предотвращающей спекание насыщающей среды.

В качестве объекта изучения были выбраны боридные покрытия на углеродистых сталях 45 и У8А, состав которых приведен в таблице 1.

Микроструктуру полученных покрытий изучали с помощью оптического микроскопа Carl Zeiss AxioObserver Z1m с использованием программных пакетов AxioVision и Thixomet Pro по методикам, описанным в [4-8].
Все смеси приготовляли по методике, описанной в работах $[9,11]$, с использованием планетарной мельницы в режиме самоизмельчения.

Образцы размерами $10 \times 15 \times 20$ мм помещали в жаростойкие контейнеры и засыпали порошковыми смесями так, чтобы расстояние от дна контейнера до нижнего слоя образцов было 10 мм, между образцами - 5 мм, от верхнего слоя образцов до верха засыпки - 15 мм. Поверх порошковой засыпки насыпали плавкий затвор $(40 \%$ буры $+60 \% \mathrm{SiC})$ толщиной 5-6 мм. Упакованные таким образом контейнеры помещали в камерную печь типа СНОЛ и выдерживали при температуре насыщения $950^{\circ} \mathrm{C} 2,5$ ч (150 минут). По истечении выдержки контейнеры извлекали из печи и охлаждали на воздухе до температуры $70-80^{\circ} \mathrm{C}$. После чего распаковывали и извлекали образцы. Извлечённые образцы промывали в мыльной воде и просушивали.

\section{3. Результаты и обсуждение}

Микроструктура полученных покрытий представлена на рисунках 1 и 2.

Как видно из представленных рисунков, диффузионные слои, полученные при насыщении из различных сред, имеют различную толщину и морфологию.

В случае насыщения из смесей №№ 1 и 2 (рис. 1 и 2), содержание углерода значительно влияет как на толщину, так и на морфологию боридного покрытия. В случае насыщения стали 45 средняя толщина боридного слоя составляет 37 (рис. 1a) и 62 мкм (рис. 1b) при насыщении из смесей № 1 и № 2 соответственно. Толщина слоя боридов при борировании стали У8А - 23 мкм (рис. 2а) при насыщении из смеси № 1 и 39 мкм (рис. 2b) - в случае применения смеси №2. Иглы боридов на стали 45 при борировании из смесей №№ 1 и 2 располагаются не по нормали к поверхности, а под некоторым углом, причем наибольшей длины достигают иглы, расположенные по границам зерен, что свидетельствует о преимущественно граничном механизме диффузии (рис. 1). Переходная зона на стали 45 представлена перлитом и имеет примерно одинаковую (800-1200мкм) протяженность. В случае борирования стали У8А из смеси № 1 боридный слой имеет гладкую границу, а для смеси № 2 игольчатое строение слоя боридов выражено слабо (рис. 2). Переходная зона представлена перлитом и имеет протяженность 1500 - 1800 мкм.

При одновременном насыщении бором, хромом и титаном из смеси № 3 содержание углерода в стали

Таблица 1. Химический состав использованных в эксперименте сталей.

Table 1. Chemical composition of steels used in the experiment.

\begin{tabular}{|c|c|c|c|c|c|c|c|c|c|c|}
\hline $\begin{array}{c}\text { Сталь } \\
\text { Steel }\end{array}$ & $\mathrm{C}$ & $\mathrm{Si}$ & $\mathrm{Mn}$ & $\mathrm{Ni}$ & $\mathrm{S}$ & $\mathrm{P}$ & $\mathrm{Cr}$ & $\mathrm{Cu}$ & $\mathrm{Mo}$ & $\mathrm{W}$ \\
\hline 45 & 0,47 & 0,32 & 0,68 & 0,22 & 0,027 & 0,014 & 0,09 & 0,07 & - & - \\
\hline У8A & 0,78 & 0,30 & 0,25 & 0,18 & 0,015 & 0,011 & 0,03 & 0,02 & 0,02 & 0,02 \\
\hline
\end{tabular}


практически не оказывает влияния на толщину диффузионного покрытия - средняя толщина слоя боридов составляет 125 мкм (рис. 1с) на стали 45 и 97 мкм (рис. 2c) на стали У8А. Иглы боридов располагаются по нормали к насыщаемой поверхности. В случае насыщения стали У8А боридные иглы несколько затупляются, сам слой заметно компактируется, с поверхности присутствует высокобористая фаза FеB, идентифицированная как методом рентгеновской дифрактометрии, так и при помощи специального травления [12-20], когда фаза $\mathrm{FeB}$ травится менее интенсивно, чем $\mathrm{Fe}_{2} \mathrm{~B}$ и основной материал (рис. 3). Средняя толщина слоя высокобористой фазы на стали 45 составляет 35 мкм (рис. 3a), на стали У8А - 18 мкм (рис. 3b). При этом по высокобористому слою на стали У8А образовались отдельные трещины, в дальнейшем могущие привести к отслоению части диффузионного покрытия. Переходная зона на обеих сталях составляет в среднем 2000 мкм и представлена перлитом (смесь феррита и карбоборидов $\mathrm{Fe}_{3}(\mathrm{C}, \mathrm{B})$ и $\left.\mathrm{Fe}_{23}(\mathrm{C}, \mathrm{B})_{6}[2,21]\right)$.

\section{4. Заключение}

По результатам работы установлено, что:

1. Введение в состав борирующей смеси карбидообразующих элементов хрома и титана способствует значительному ускорению процессов диффузии бора в углеродистых сталях 45 и У8А.

2. При одновременном многокомпонентном насыщении бором, хромом и титаном скорость образова-

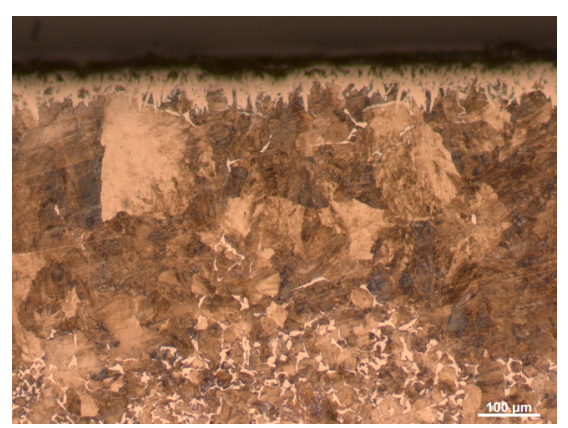

a

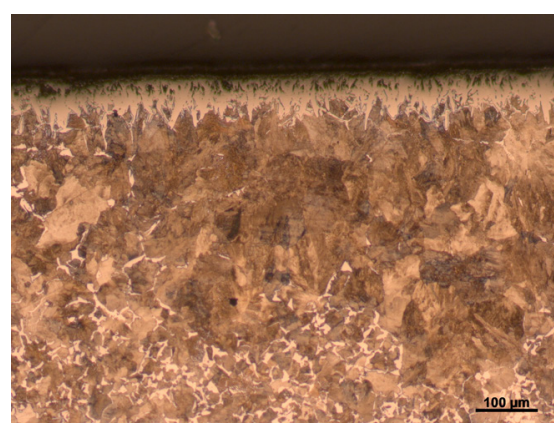

$\mathrm{b}$

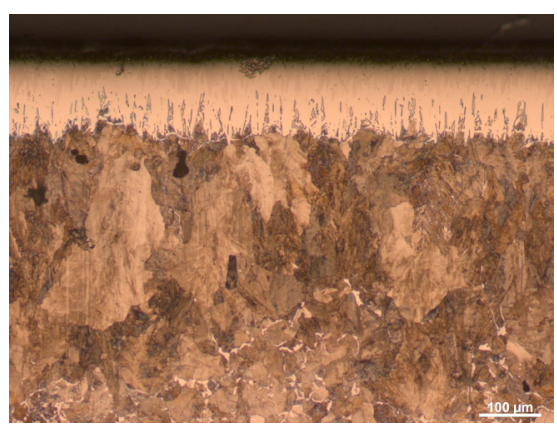

C

Pис. 1. (Color online) Микроструктура диффузионных покрытий на стали 45: (а) - смесь № 1, (b) - смесь № 2 , (c) - смесь № 3 . Fig. 1. (Color online) Microstructure of diffusion coatings on steel 45: (a) - a mixture № 1, (b) — a mixture №2, (c) — a mixture № 3.

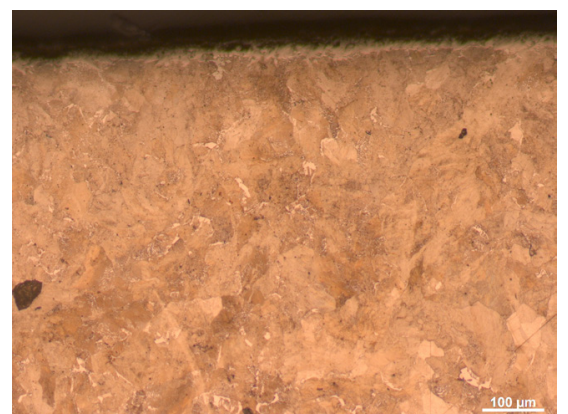

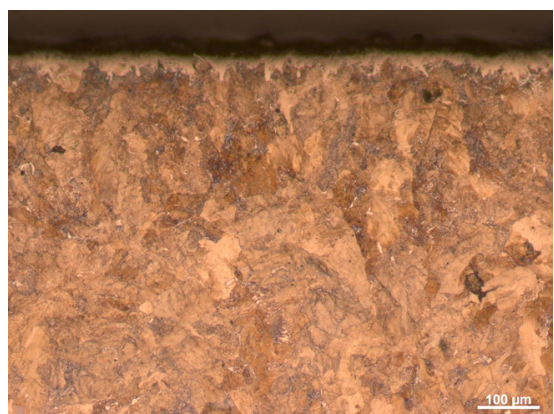

$\mathrm{b}$

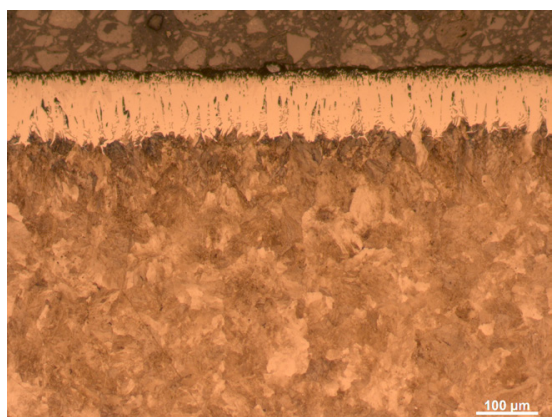

Pис. 2. (Color online) Микроструктура диффузионных покрытий на стали У8А: (а) - смесь № 1, (b) - смесь № 2, (c) - смесь № 3. Fig. 2. (Color online) Microstructure of diffusion coatings on steel U8A: (a) - a mixture № 1, (b) - a mixture № 2, (c) - a mixture № 3.

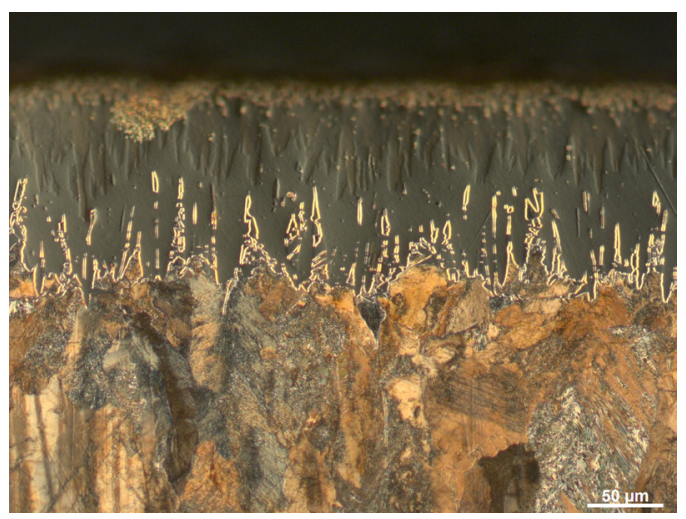

a

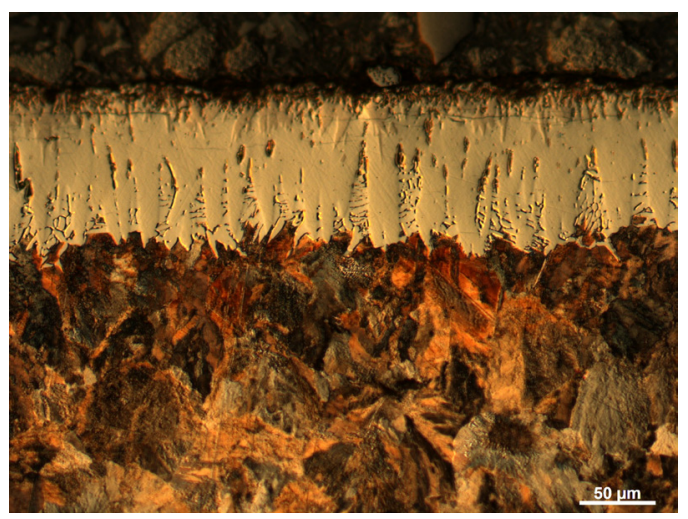

$\mathrm{b}$

Pис. 3. (Color online) Морфология боридных слоев при насыщении из смеси № 3: (а) сталь 45, (b) сталь У8А

Fig. 3. (Color online) The morphology of boride layers at saturation of the mixture № 3: (a) steel 45, (b) steel U8A 
ния диффузионного слоя на углеродистых сталях выше, чем при борировании.

3. В случае многокомпонентного насыщения бором совместно с сильными карбидообразующими элементами (хром и титан) увеличение содержания углерода в насыщаемой углеродистой стали от 0,45 до 0,8 мас.\% оказывает слабое влияние на процесс образования диффузионного слоя в отличие от однокомпонентного насыщения бором.

\section{Литература/References}

1. Voroshnin L.G. Borirovanie promishlennikh stalej i chugunov. Textbook. Spravochnoe posobie. Minsk, Belarus. (1981) 205p. (in Russian) [Ворошнин Л.Г. Борирование промышленных сталей и чугунов. Справочное пособие. Минск, Беларусь. 1981. 205c.]

2. Mosorov V.I., GreshilovA. D.,LigdenovB. D., Polzunovskij vestnik. 1 (1) 206 (2012) (in Russian) [Мосоров В.И., Грешилов А.Д., Лыгденов Б.Д. Ползуновский вестник. 1 (1) 206 (2012).]

3. Patent RF 2011148197/02, 25.11.2011 (in Russian) [Патент РФ 2011148197/02, 25.11.2011]

4. Kazakov A. A., Kiselev D. Metallography, Microstructure, and Analysis. DOI 10.1007/s13632-016-0289-6

5. Kazakov A.A., Ryaboshuk S., Lyubochko D., Chigintsev L. Microscopy and Microanalysis. 3 (21) 1775 (2015). DOI:10.1017/S1431927615009551

6. Kazakov A.A. and Kiselev D. Microscopy and Microanalysis. 3 (21) 457 (2015). DOI $10.1017 /$ S1431927615003086.

7. Kazakov A.A., Luong N.H., Kasakova E.I., Zorina E. M. Proceedings of the $32^{\text {nd }}$ Annual Convention of the International Metallographic Society Held "Understanding Processing, Structure, Property and Behavior Correlations". Cincinati, Ohio ASM International. (1999) p. 133 - 142.

8. Kazakov A.A., Kovalev P.V., Myasnikov A.L., Drobinin A.A., Zinchenko S.D. Chernyie metally. 232 (2006) (in Russian). [Казаков A.A., Ковалев П.В., Мясников А.Л., Дробинин А.А., Зинченко С. Д. Черные металлы. 232 (2006).]

9. Syarifah Yunus, Siti Khadijah Alias, Freddawati Rashiddy Wong, Amirul Abd. Rashid and Nik Rosli Abdullah. Journal of Engineering and Applied Sciences. 1017 (2015).

10. Ivanov S.G., Garmaeva I.A., Guriev M.A., Guriev A.M., Starostenkov M.D. Lecture Notes in Mechanical Engineering. 4922 (2015). DOI: 10.1007/978-3-319-15684-2_7

11. Ivanov S.G., Guriev A.M., Starostenkov M.D., Ivanova T. G., Levchenko A. A. Russian Physics Journal. 2 (57) 266 (2014). DOI:10.1007/s11182-014-0234-6

12. Yu, L. G., Chen, X. J., Khor, K. A., \& Sundararajan, G.. Acta Materialia. 8 (53) 2361 (2005).

13. Zuno-Silva J., Ortiz-Domínguez M., Keddam M., EliasEspinosa M., Damián-Mejía O., Cardoso-Legorreta E., Abreu-Quijano M. J. Min. Metall. Sect. B-Metall. 2 (50) 101 (2014).

14. Calik A., Gencer Y., Tarakci M., Gunduz K.O. and Gulec A.E. Acta physica polonica a. 2 (123) 449 (2013). DOI: 10.12693/APhysPolA.123.449.

15. Gunes I., Kayali Yu. and Ulu S. Indian Journal of Engineering \& Material Sciences. 19397 (2012).

16. Campos-Silva I. JESTECH. 2 (15) 53 (2012).

17. Milinović A., Krumes D., Marković R. Technical Gazette. 1 (19) 27 (2012).

18. KENDALL RALPH S., UNITED STATES PATENTS 3,806,374 Patented Apr. 23, 1974.

19. Sutrisno, Soegijono B. and Hikam M. Research Journal of Material Sciences. 1 (10) 1 (2013)

20. Ibrahim Gunes, Melih Ozcatal. Materials and technology. 5 (49) 759 (2015).

21. Guriev A. M., Kozlov E. V., Lygdenov B. D., Kirienko A. M., Chernyh E. V. Fundamental'nye problemy sovremennogo materialovedenija. 1 (2) 54 (2004). (in English) [Guriev A. M., Kozlov E. V., Lygdenov B. D., Kirienko A. M., Chernykh E.V. Фундаментальные проблемы современного материаловедения. 1 (2) 54 (2004).] 